\title{
Regionalni aspekt ekološke poljoprivrede Hrvatske
}

\section{Sažetak}

Republika Hrvatske u svim strateškim dokumentima poljoprivrednog razvitka polazi i od uvažavanja značajnih regionalnih razlika. Klimatske i pedološke razlike povijesno su determinirale vrste i intenzitet proizvodnji te su dobra osnova budućeg poljoprivrednog razvitka koji bi se temeljio na regionalnoj sinergiji. U tome, a zahvaljujući rastu potražnje za proizvodima iz ekološkog uzgoja, sve je veći broj ekoloških proizvođača koji su još uvijek nedovoljno tržno zastupljeni. U 2018. godine je u Hrvatskoj bilo registrirano 4.373 eko proizvođača te se predviđa da bi ih do 2025. godine bilo oko 6.100. U razdoblju od 2013. do 2018. godine bilježi se veliko povećanje površina ekološkog poljoprivrednog zemljišta i to s 40.660 na 103.166 ha. Najveće povećanje imaju trajni travnjaci (2,8 puta), zatim trajni nasadi (2,5 puta) te oranice $(2,4$ puta) koje čine ispod polovice ukupnih ekoloških površina $(48,7 \%)$. Najviše površina u ekološkom uzgoju nalazi se u Panonskoj (39,0\%), manje u Jadranskoj (36,9\%) te najmanje u Središnjoj Hrvatskoj (24,1\%). Panonska Hrvatska posjeduje 66,7\% ukupnih oranica i vrtova u ekološkom uzgoju, Središnja Hrvatska 39,3\% površina trajnih nasada (39,3\%) te Jadranska Hrvatska čak 74,0\% površina ukupnih trajnih travnjaka Hrvatske koji su u ekološkom uzgoju. U ukupnoj ekološkoj proizvodnji značajnije su zastupljena žita (14,87\%) i voće (11,52\%), a od pojedinačnih kultura su pšenica ozima, kukuruz, ječam ozimi, pravi pir, tritikale ozime, zob jara, orah, lijeska išljiva.

Ključne riječi: ekološka poljoprivreda, regija, proizvodnja, Hrvatska

\section{Uvod}

Mnoštvo je definicija ekološke poljoprivrede te je ona prema Deže i sur. 2016. str. 64., „sustav gospodarenja koji teži etički prihvatljivoj, ekološki čistoj, socijalno pravednoj i gospodarski isplativoj poljoprivrednoj proizvodnji“. Njene začetke neki vide čak u i u tradicionalnoj seljačkoj poljoprivredi i ekonomiji, pa su, prema njima, ta iskustva dragocjena za organiziranje obiteljske ekološke poljoprivrede(Cifrić, 2003) i danas.

Principi ekološke proizvodnje postaju prihvatljivi na globalnoj razini te se bilježi povećanje resursa i količina proizvedenih u Svijetu. Prisutne su značajne razlike između zemalja, ali i u pojedinim razvijenim zemljama postoje velike regionalne razlike u zastupljenosti ekološke poljoprivrede u ukupnoj poljoprivrednoj proizvodnji.

Na zastupljenost ekološke u ukupnoj poljoprivrednoj proizvodnji djeluje mnoštvo čimbenika. Jedan od čimbenika je potencijal za ekološku proizvodnju koji određuju ukupni raspoloživi poljoprivredni resursi (poljoprivredno zemljište, radna snaga te strojevi i oprema) i klimatski uvjeti područja proizvodnje. S druge strane, tržište odnosno potražnja za proizvodima iz ekološke proizvodnje potiče proizvođače da se uključuju u takvu proizvodnju, ali i da povećaju proizvedene količine.

$\mathrm{Na}$ globalnoj razini primjetna je neravnomjernost između proizvođača i potrošača. Gospodarski razvijene države bilježe velik rast potražnje za ekološki proizvedenim proizvodima, što ga čini jednim od najbrže rastućih tržišta. Velika potražnja se podmiruje uvozom iz manje

prof. dr. sc. Ivo Grgić, Sveučilište u Zagrebu Agronomski fakultet, Svetošimunska cesta 25, 10000 Zagreb, Hrvatska

dr.sc. MarinČagalj,Institutzajadranskekultureimelioracijukrša,PutDuilova11,21000Split,Hrvatska

Lucija Baškarić, dipl. ing. agr., Agronomska škola Zagreb, Gjure Prejca 2, 10040 Zagreb

doc. dr. sc. Jernej Prišenk, Univerza v Mariboru, Fakulteta za kmetijstvo in biosistemske vede, Pivola 10, 2311 Hoče, Slovenia

Autor za korespondenciju: igrgic@agr.hr 
gospodarski razvijenih država gdje se bilježi povećanje potražnje za konvencionalno proizvedenim prehrambenim proizvodima. Tako je najviše površina pod ekološkom proizvodnjom u Australiji (35,6 milijuna ha) koja čini gotovo polovinu svjetskih površina pod ekološkom poljoprivredom. Slijede je Argentina s 3,4 milijuna ha i Kina s 3 milijuna ha. U Europskoj uniji je 2017. godine bilo 12,8 milijuna ha odnosno 7,2\% ukupnih obradivih poljoprivrednih površina. (Grgić i sur., 2019).

U 2017. godini u svijetu je bilo registrirano 2,9 milijuna ekoloških proizvođača ( $F i B L, 2019)$ od čega 40\% u Aziji, 28\% Africi te 16\% Latinskoj Americi. (Grgić i sur. 2019).

Republika Hrvatska bilježi znatno povećanje površina uključenih u ekološku proizvodnju, ali i povećanje potražnje te prihvaćanja ekoloških principa i kod proizvođača i potrošača (Čagalj i sur., 2016). Kod proizvodnje se naglašava potreba veće količinske proizvodnje, te bolje korištenje regionalne različitosti Hrvatske. Potrošači često ističu manjak ponude i/ili relativno visoku cijenu u odnosu na njihov dohodak. Prema procjeni USDA (United States Department of Agriculture) iz 2018. godine, hrvatsko tržište ekološki proizvedene hrane se procjenjuje na više od 100 milijuna $€$, pri čemu je većina proizvoda uvezena. Ekološki proizvodi se prema analizama USDA najviše prodaju u velikim trgovačkim lancima, lancima drogerija i ekološkim franšizama, dok se mali dio trži u malim privatnim trgovinama ekoloških proizvoda. (Grgić i sur., 2019).

Potražnja domicilnog stanovništva će i na dalje biti limitirana dohodovnom izdašnošću, a nastup hrvatskih proizvođača na inozemnim tržištima ograničen je malim količinama proizvoda (Grgić i sur. 2019). Zbog toga kao velika prilika ekoloških proizvođača nameće se ekološka proizvodnja u neposrednoj blizini velikih potrošačkih tržišta više dohodovne izdašnosti. „Blizina tržišta omogućuje i prodaju „od polja do stola“ pri čemu je to posebno pogodno za povrće i jagodičasto voće“ (Grgić, - 2014, str. 9). Općenito,,,potrošači razvijenog gospodarstva sve veći naglasak stavljaju na kakvoću, sljedivost i sigurnost proizvoda“ (Vrdoljak, - 2009).

\section{Materijal i metode}

Za potrebe analize u radu smo Republiku Hrvatsku podijelili u tri regije s pripadajućim županijamaito:

- Panonska Hrvatska: Brodsko-posavska, Osječko-baranjska, Požeško-slavonska, Virovitičko-podravska i Vukovarsko-srijemska županija

- Središnja Hrvatska: Bjelovarsko-bilogorska, Grad Zagreb, Karlovačka, Koprivničko-križevačka, Krapinsko-zagorska, Međimurska, Sisačko-moslavačka, Varaždinska i Zagrebačka županija

- Jadranska Hrvatska: Dubrovačko-neretvanska, Istarska, Ličko-senjska, Primorsko-goranska, Splitsko-dalmatinska, Šibensko-kninska i Zadarska županija.

Analiza se odnosi na razdoblje nakon pristupanja Hrvatske u EU 2013. godine. U radu se detaljnije analiziraju skupine s udjelom iznad 5,01 \% ukupnih površina u ekološkoj proizvodnji, u ovom slučaju žita $(14,87 \%)$ i voće $(11,52 \%)$. Također, kod istih skupina detektirani su te analizirani proizvodi s udjelom iznad 5,01\% površina i to su pšenica ozima, kukuruz, ječam ozimi, pravi pir, tritikale ozime, zob jara, orah, lijeska išljiva.

Za potrebe rada korišteni su podaci Državnog zavoda za statistiku Republike Hrvatske, Ministarstvo poljoprivrede tj. iz AGRONET sustava te dostupna relevantna literatura. $U$ radu je korišten desk research odnosno secondary research pristup, a za kratkoročno projiciranje određenih pojava uporabljena je metoda linearnog trenda prvog stupnja.

\section{Rezultati i rasprava}

Početkom novog milenija u Hrvatskoj se pojavljuju prvi poljoprivredni eko proizvođači te ih je u 2005. godini bilo 269. Do pristupanja Hrvatske u EU, 2013. godine, njihov broj se uve- 
ćao pet puta te je krajem 2012. bilo 1.528 ekološka poljoprivredna proizvođača. S povećanjem njihova broja povećava se i do tada malo tržište eko proizvoda pri čemu se bilježi brži rast potražnje od ponude. Potrošači brže prihvaćaju kvalitativne novine nego što to čine u pravilu konzervativniji proizvođači.

Nakon pristupa Hrvatske EU otvara se znatno veće tržište, te se povećava i broj registriranih subjekata u ekološkoj proizvodnji.

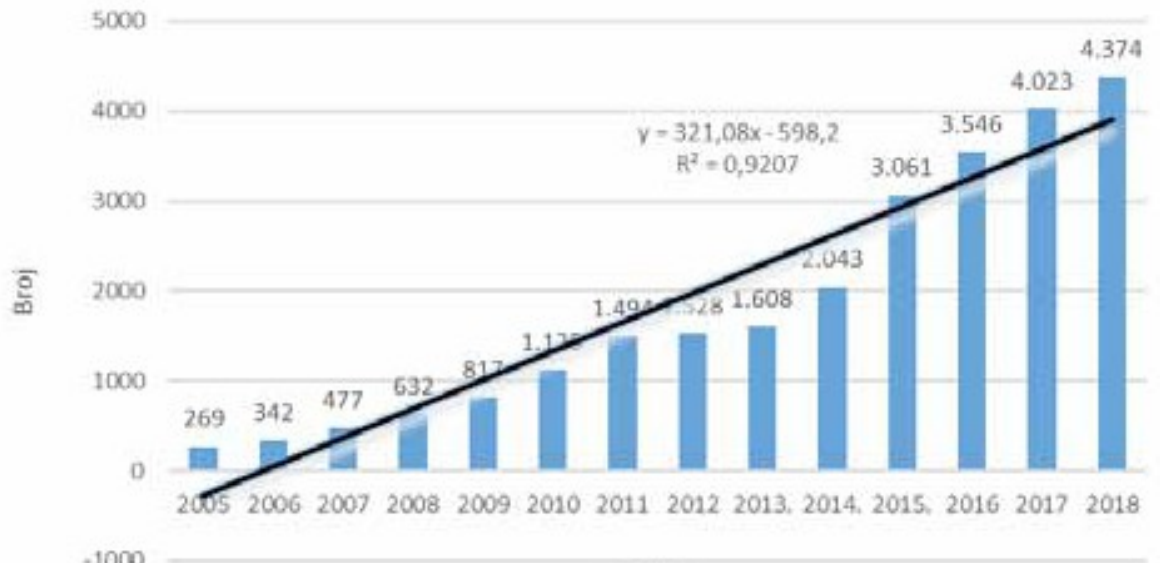

Godina

Grafikon 1. Broj ekoproizvođača u Republici Hrvatskoj od 2005. do 2018. godine

Graph 1. Number of ecological agricultural producers in Croatia from 2005 to 2018

Izvor: Izračun prema „Tražene kulture na jedinstvenom zahtjevu“ https://www.apprrr.hr/agronet/ za pojedine godine

Source: Calculation based on "Requested cultures on a single request" https://www.apprrr.hr/agronet/

Tako je 2018. godine u Hrvatskoj bilo registrirano 4.373 eko proizvođača pri čemu se i dalje predviđa njihovo znatno povećanje te bi ih do 2025. godine bilo oko 6.100.

U razdoblju od 2013. do 2018. godine bilježi se i značajan povećanje površina ekološkog poljoprivrednog zemljišta i to s 40.660 na 103.166 ha. Najveće povećanje bilježe trajni travnjaci (2,8 puta), zatim trajni nasadi (2,5 puta) te oranice (2,4 puta) koje čine manje od polovice ukupnih ekoloških površina $(48,7 \%)$.

Proizvodne eko površine su i dalje prosječno male te je i proizvodnja, unatoč povećanju ukupnih površina, i dalje mala. U 2018. godini u Hrvatskoj je proizvedeno oko 22 tisuće tona pšenice, raži 357 tona, ječma 4.114 tone, zobi 2.206 tona te kukuruza suhog zrna 21.226 tona.

Najviše površina u ekološkoj proizvodnji je u vlasništvu obiteljskih poljoprivrednih gospodarstava (58,9\%), manje trgovačkih društava $(27,5 \%)$, obrta $(8,9 \%)$, te zadruga $(4,6 \%)$. Zbog strukture poljoprivrednih površina u prosjeku su to veće površine po vlasniku ( 8,5 ha) pri čemu su najveće kod zadruga (38,1 ha), a najmanje kod OPG-ova (6,0 ha) ili ukupno 8,5 ha.

U strukturi ekoloških površina u 2019. godini najveći udjel su imali krški pašnjaci $(25,8 \%)$ te krmno bilje (19,76\%). Manji udjel je žita (14,9\%), voća (11,52\%) te uljarica $(5,2 \%)$,

Kod voća, s udjelom iznad $5 \%$ ukupnih površina su orah (42,5\%), lijeska (24,3\%), te šljiva $(6,8 \%)$. Značajnije udjele imaju i jabuka $(4,4 \%)$, višnja $(3,6 \%)$ te aronija $(3,4 \%)$. S manjim površinama i udjelima pojavljuju se smokva, badem, kesten, marelica, kruška, borovnica, breskva, kupina, šipak, bazga itd. 
Najveći broj proizvođača je uključen u proizvodnju oraha (1.069), lijeske (814), miješanog voća (792), šljive (515), aronije (341), jabuke (180), a ostalih proizvođača je pojedinačno ispod 100.

Prosječne površine po proizvođaču su najveće kod proizvodnje višnje (4,9 ha), zatim oraha (4,8 ha), smokve (3,7 ha), lijeske (3,6 ha) te jabuke (3,0 ha).

Nešto veće su količine industrijskog bilja, te je proizvedeno $8.898 \mathrm{t}$ uljane repice, suncokreta $6.047 \mathrm{t}$ i soje $5.594 \mathrm{t}$.

Proizvodi se i aromatsko, ljekovito i začinsko bilje (3.939 t). Proizvedene su male količine mahunarki suhog zrna (65 t) te ukupno krumpira (240 t).

Male su količine povrća iz ekološke proizvodnje te je ukupno, uključujući i jagode, proizvedeno $2.151 \mathrm{t}$ (od toga jagode samo $36 \mathrm{t}$ ).

\section{Regionalni razmještaj ekoloških površina i proizvodnje}

Značajne su regionalne razlike zastupljenosti pojedinih kategorija površina tako da su dvije trećine $(66,7 \%)$ ekoloških oranica i vrtova u Panonskoj, najveće površine trajnih nasada (39,3\%) u Središnjoj Hrvatskoj te je čak 74,0\% površina trajnih travnjaka u Jadranskoj Hrvatskoj. Ovo je uvjetovano strukturom površina po pojedinim regijama jer u Panonskoj oranice i vrtovi čine 80,4\% površina u ekološkoj proizvodnji regije, u Središnjoj Hrvatskoj su također oranice i vrtovi najzastupljeniji $(39,3 \%)$ te su u Jadranskoj to trajni travnjaci s udjelom od $80,8 \%$ ukupnih eko površina regije.

Najveće korištene površine u ekološkom sustavu se nalaze u Panonskoj (39,0\%), manje u Jadranskoj Hrvatskoj (36,9\%) te najmanje u Središnjoj Hrvatskoj (24,1\%).

Najveći broj proizvođača je u Središnjoj Hrvatskoj, a prerađivača u Jadranskoj (Grafikon 2).

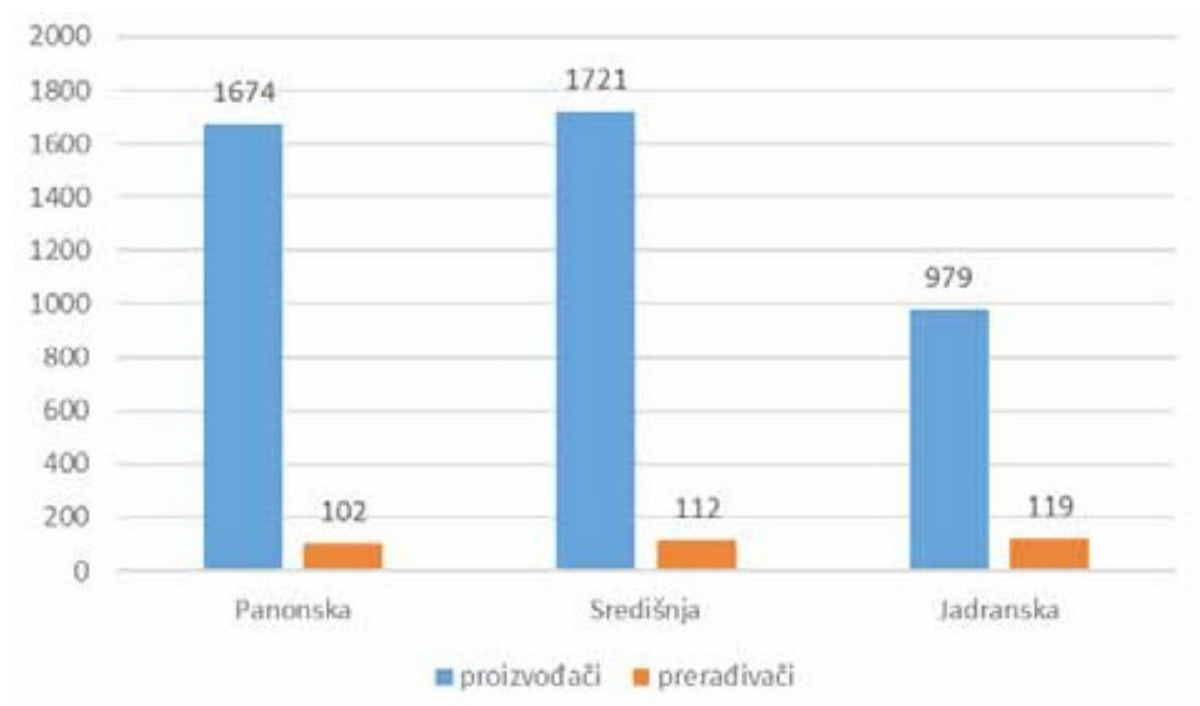

Grafikon 2. Regionalni razmještaj ekoloških proizvođača i prerađivača u 2018. godini Graph 2. Regional distribution of organic producers and processors in 2018. Izvor: Izračun prema,,Broj ekoloških poljoprivrednih subjekata, Županije“, DZD RH Source: Calculation based on „Number of organic agricultural subjects, Counties“, DZD Croatia 
Velika je razlika u ekološkim površinama po županijama i najveće površine su u Osječkobaranjskoj županiji (19.324 ha) koja ima i najveći broj ekoloških proizvođača (1.770). Najmanje površine su u Krapinsko-zagorskoj županiji (159 ha), a najmanji broj eko proizvođača u Dubrovačko-neretvanskoj županiji (137).

\section{Ekološka proizvodnja žita}

Pod žitima je bilo 15.611 ha površina pri čemu je najviše pod pšenicom (37\%), kukuruzom (21\%), ječmom (10,9\%), pravim pirom (8,3\%), tritikale ozimim (6,8\%), jarom zobi $(5,9 \%)$. Ostala žita pojavljuj se u manjim udjelima kao što su heljda, ozima zob i raž, jari ječam, jara pšenica, tvrda pšenica, proso, sirak itd. pojavljuje se s manjim udjelima.

Relativno je mali broj eko proizvođača pojedinih žita. Najviše ih proizvodi pšenicu (246) te kukuruz (243), a manje ih proizvodni jaru zob, ozimi ječam, ozime tritikale i pravi pir. U proizvodnji nekih žita nalazi je po nekoliko ili samo jedan proizvođač.

Male ukupne površine za posljedicu imaju i prosječno male površine po proizvođaču te su one kod ozime pšenice 23 ha, kukuruza 14 ha, pravog pira 12 ha te kod ozimog ječma i ozime raži po 10 ha.

Većina površina je u Panonskoj (80,6\% ukupnih površina pod žitima), znatno manje u Središnjoj Hrvatskoj (16,15\%), te 3,3\% u Jadranskoj Hrvatskoj.

U prosjeku se žita u Hrvatskoj proizvode na 11 ha sa značajnim regionalnim razlikama pri čemu u Panonskoj Hrvatskoj na 17 ha, Središnjoj 5 ha, te Jadranskoj 4 ha.

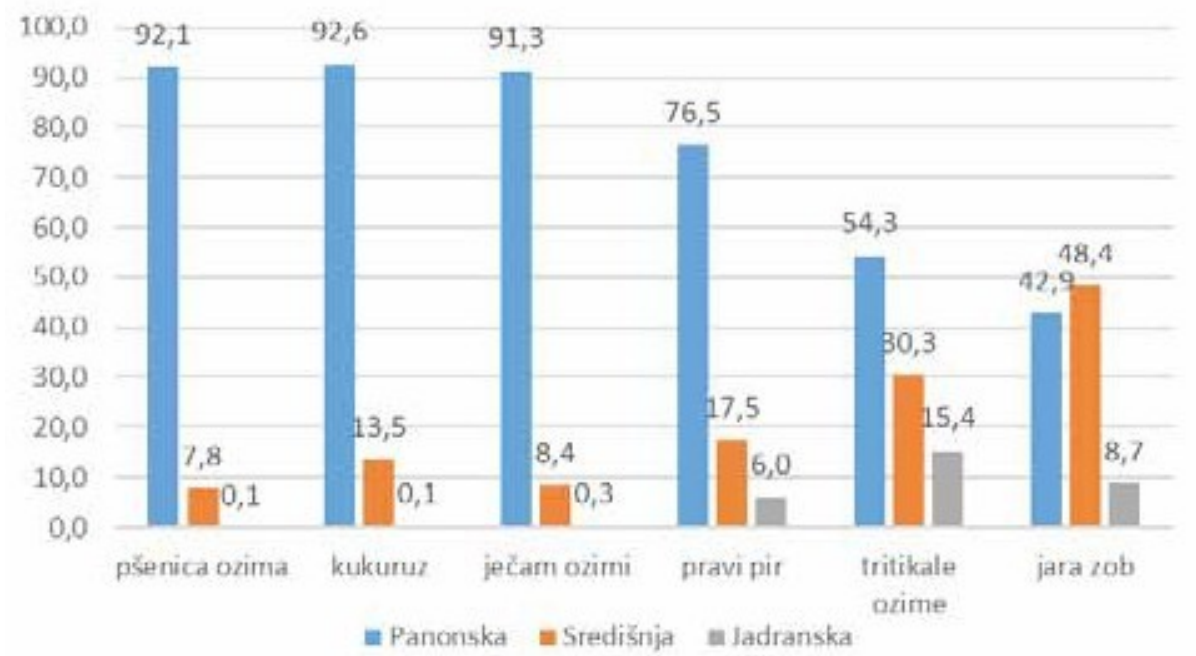

Grafikon 3. Regionalna struktura ekoloških površina nekih žita u 2019. godini

Graph 3. Regional structure of organic agricultural area of some wheats in 2019.

Izvor: Preračunato prema podacima „Tražene kulture na jedinstvenom zahtjevu 2019“, https://www.apprrr.hr/agronet/

Source: Calculated according data „Required cultures on a single request in 2019“, https:// www.apprrr.hr/agronet/

Pravi pir je žitarica slična pšenici, samo s malo većim zrnom, a iznimno je probavljiva. Za razliku od obične pšenice sadrži 10 - 12\% više proteina. Koristi se u proizvodnji raznih vrsta 
peciva, tjestenina, kolača, itd. U novije vrijeme sve se više uzgaja i postala je vrlo cijenjena od raznih alergičara. Najveće proizvodne površine pravog pira (994 ha) su u Panonskoj Hrvatskoj, manje u Središnjoj (228 ha), a najmanje u Jadranskoj (77 ha)

Pšenoraž (tritikale) je sitnozrna žitarica, križanac pšenice (Triticum) i raži (Secale). Stvoreni su brojni kultivari koji imaju bolji aminokiselinski sastav od raži, a po sadržaju energije je slična pšenici. Najveće površine se također nalaze u Panonskoj Hrvatskoj (577 ha).

Veličina i struktura površina odredile su i značaj pojedinih županija u ekološkoj proizvodnji žita.

Najveće površine pod ekološkom proizvodnjom žita su u Osječko-baranjskoj županiji (6.230 ha) te znatno manje u Virovitičko-podravskoj (2.636 ha). I po broju proizvođača vodeća je Osječko-baranjska s 354 proizvođača, a na drugom mjestu je Brodsko-posavska s 134 proizvođača.

\section{Ekološka proizvodnja voća}

Najviše površina ekološke proizvodnje voća je u središnjoj Hrvatskoj (49,8\%), neznatno manje (49,4\% u Panonskoj te samo 6,8\% u Jadranskoj Hrvatskoj.

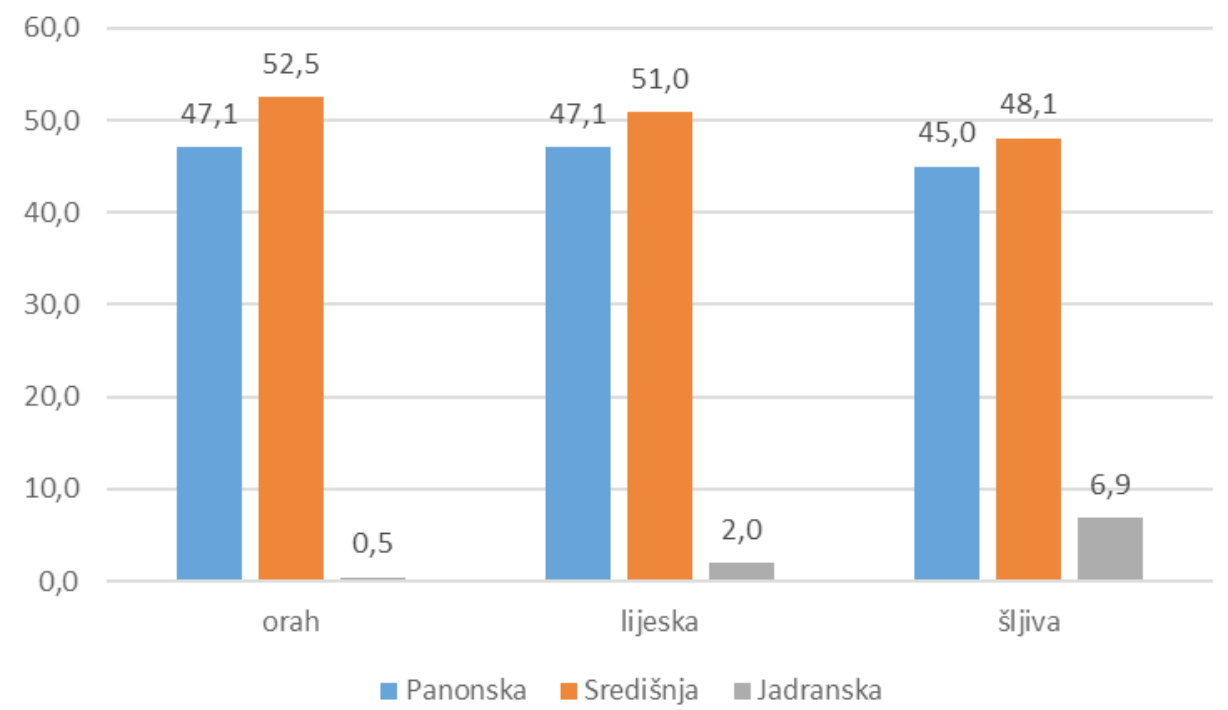

Grafikon 4. Regionalna struktura ekoloških površina nekih voćnih vrsta u 2019. godini

Graph 4. Regional structure of organic agricultural area of some fruit species in 2019.

Izvor: Preračunato prema podacima „Tražene kulture na jedinstvenom zahtjevu 2019“, https://www. apprrr.hr/agronet/

Source: Calculated according data,,Required cultures on a single request in 2019“

Prosječna površina po proizvođaču je 4,8 ha oraha pri čemu je u Središnjoj Hrvatskoj 5,1 ha, Panonskoj 4,6 te u Jadranskoj 1,8 ha gdje se pojavljuje samo 13 proizvođača.

Prosječno manje površine su pod lijeskom $(2,6$ ha) pri čemu nisu kao kod oraha tako velike regionalne razlike (Panonskoj 3,8 ha, Središnjoj 3,5 te Jadranskoj 3,0 ha).

$\mathrm{U}$ ekološkoj proizvodnji je prosječno po proizvođaču 1,6 ha šljiva pri čemu je najviše u središnjoj Hrvatskoj (2,7 ha), Panonskoj 1,4 te Jadranskoj 0,5 ha.

Najveće površine voća u ekološkom uzgoju su u Osječko-baranjskoj županiji (2.272 ha), te 
znatno manje u Bjelovarsko-bilogorskoj županiji (1.302 ha). Najmanje površine su u Šibensko-kninskoj županiji (63 ha). I po broju ekoloških proizvođača najvažnija je Osječko-baranjska (651) te Karlovačka županija 456, dok ih najmanje ima Šibensko-kninska županija (24).

Vodeća županija po površinama ekološkog uzgoja oraha je Osječko-baranjska županija (970 ha) kao i kod lijeske (663 ha), a kod šljiva Karlovačka županija (288 ha). Po broju ekoloških proizvođača oraha vodeća je također Osječko-baranjska županija s 175 proizvođača, lijeske (122), te šljive (83).

\section{Zaključak}

lako je došlo do značajnog povećanja broja eko proizvođača i prerađivača, njihov tržni udjel u ukupnoj poljoprivrednoj proizvodnji je još mali. Ekološki uvjeti Hrvatske dobra su osnova za povećanje ukupne ekološke poljoprivredne proizvodnje pri čemu veliku ulogu ima i korištenje regionalnih različitosti ukupnog proizvodnog prostora.

Godine 2018. godine u Hrvatskoj je bilo registrirano 4.373 eko proizvođača te se projicira njihovo povećanje do 2025. godine na oko 6.100. U razdoblju od 2013. do 2018. godine u Hrvatskoj se značajno povećale površine ekološkog poljoprivrednog zemljišta i to s 40.660 na 103.166 ha. Najveće povećanje imaju trajni travnjaci (2,8 puta), trajni nasadi (2,5 puta) te oranice $(2,4$ puta). Proizvodne eko površine su i dalje prosječno male te je i proizvodnja, unatoč povećanju ukupnih površina, i dalje mala. U 2018. godini u Hrvatskoj je proizvedeno oko 22 tisuće tona pšenice, raži 357 tona, ječma 4.114 tone, zobi 2.206 tona te kukuruza suhog zrna 21.226 tona.

Značajne su regionalne razlike zastupljenosti pojedinih kategorija površina. Dvije trećine $(66,7 \%)$ ekoloških oranica i vrtova su u Panonskoj, najveće površine trajnih nasada (39,3\%) u Središnjoj Hrvatskoj te je čak 74,0\% površina trajnih travnjaka u Jadranskoj Hrvatskoj. Ovo je uvjetovano strukturom površina po pojedinim regijama jer u Panonskoj oranice i vrtovi čine 80,4\% površina u ekološkoj proizvodnji regije, u Središnjoj Hrvatskoj su također oranice i vrtovi najzastupljeniji (39,3\%), ali su u Jadranskoj to trajni travnjaci s udjelom od $80,8 \%$ ukupnih eko površina regije.

Regionalne razlike su uvjetovane najviše klimatsko-pedološkim razlikama pojedinih regija, a manje tradicijom proizvodnji, proizvodno-ekonomskim obilježjima proizvođača te potražnjom na lokalnom tržištu za proizvodima iz ekološkog uzgoja.

\section{Literatura}

Cifrić, I. (2003) Značaj iskustva seljačke poljoprivrede za ekološku poljoprivredu, Sociologija i prostor : časopis za istraživanje prostornoga i sociokulturnog razvoja 41 (1-2), 5-27

Čagalj, M., Haas, R., Morawetz, U. (2016) Effects of quality claims on willingness to pay for organic food. Evidence from experimental auctions in Croatia, British Food Journal 118 (9), 2218-2233

Deže, J., Ranogajec, LJ., Lončarić, R., Rabik, M. (2016) Mogućnosti razvoja poduzetništva u ekološkoj poljoprivredi Vukovarsko-srijemske županije Poljoprivreda 22 (2), 64-69

Grgić, I., Ivanković, M., Cagalj, M., Miličević, M., Zrakić Sušac, M. (2019) Ekološka poljoprivredna proizvodnja Hrvatske i turizam, Glasnik zaštite bilja 42 (4), 14-19

Grgić, I., Zrakić, M., Georgievski, D. (2014) Ekološka i integrirana poljoprivredna proizvodnja na vodozaštitnom području grada Zagreba, Glasnik Zaštite Bilja 37(6), 9-17

Miljković, I. (1995) Regionalizacija uzgoja jabuke u Hrvatskoj, Agronomski glasnik: Glasilo Hrvatskog agronomskog društva 57 (6), 381-401

Vrdoljak, M., Kegalj, A., Čalić, S. (2009) Ekološka proizvodnja zemalja srednje Europe, Stočarstvo: Časopis za unapređenje stočarstva 63 (4), 207-308

https://www.apprrr.hr/agronet/ , Tražene kulture na jedinstvenom zahtjevu, pristupljeno 20.5.2020.

https://www.dzs.hr/App/PXWeb/PXWebHrv/Menu.aspx?px_tableid=EP61.px\&px_path=Poljoprivreda,\%20 lov,\%20\%C5\%A1 umarstvo\%20i\%20ribarstvo_Ekolo\%C5\%A1ka\%20poljoprivreda\&px_language=hr\&px $\mathrm{db}=$ Poljoprivreda,\%20lov,\%20\%C5\%A1umarstvo\%20i\%20ribarstvo\&rxid=fc9d580f-2229-4982-a72c-cdd3e96307d3, Broj ekoloških poljoprivrednih subjekata, Županije, pristupljeno 15.5.2020. 


\title{
Regional aspect of organic agriculture in Croatia
}

Review paper

\begin{abstract}
All strategic documents of agricultural development of the Republic of Croatia starts from respecting significant regional differences. Climatic and pedological differences have historically determined the types and intensity of production and are a good basis for future agricultural development which is based on regional synergy. Concerning that, and thanks to the growing demand for organic products, there is a growing number of organic producers who are still under-represented. In 2018, there were registered 4,373 eco-producers in Croatia, and it is estimated that by 2025 there will be around 6,100. In the period from 2013 to 2018, there was a large increase in the area of organic agricultural land from 40,660 to 103,166 ha. The largest increase is in permanent grasslands (2,8 times), followed by permanent crops $(2,5$ times) and arable land $(2,4$ times), which make up less than half of the total ecological area (48,7\%). Most areas in organic farming are located in Pannonia (39,0\%), less in the Adriatic (36,9\%) and the least in Central Croatia (24,1\%). Pannonian Croatia owns 66,7\% of the total arable land and gardens in organic farming, Central Croatia 39,3\% of the area of permanent crops (39,3\%) and Adriatic Croatia as much as 74,0\% of the total permanent grassland of Croatia that is in organic farming. In the total organic production, cereals $(14,87 \%)$ and fruits $(11,52 \%)$ are more significant, and individual crops include winter wheat, corn, winter barley, spelled, winter triticale, spring oats, walnuts, hazelnuts and plums.
\end{abstract}

Keywords: organic agriculture, region, agricultural production, Croatia

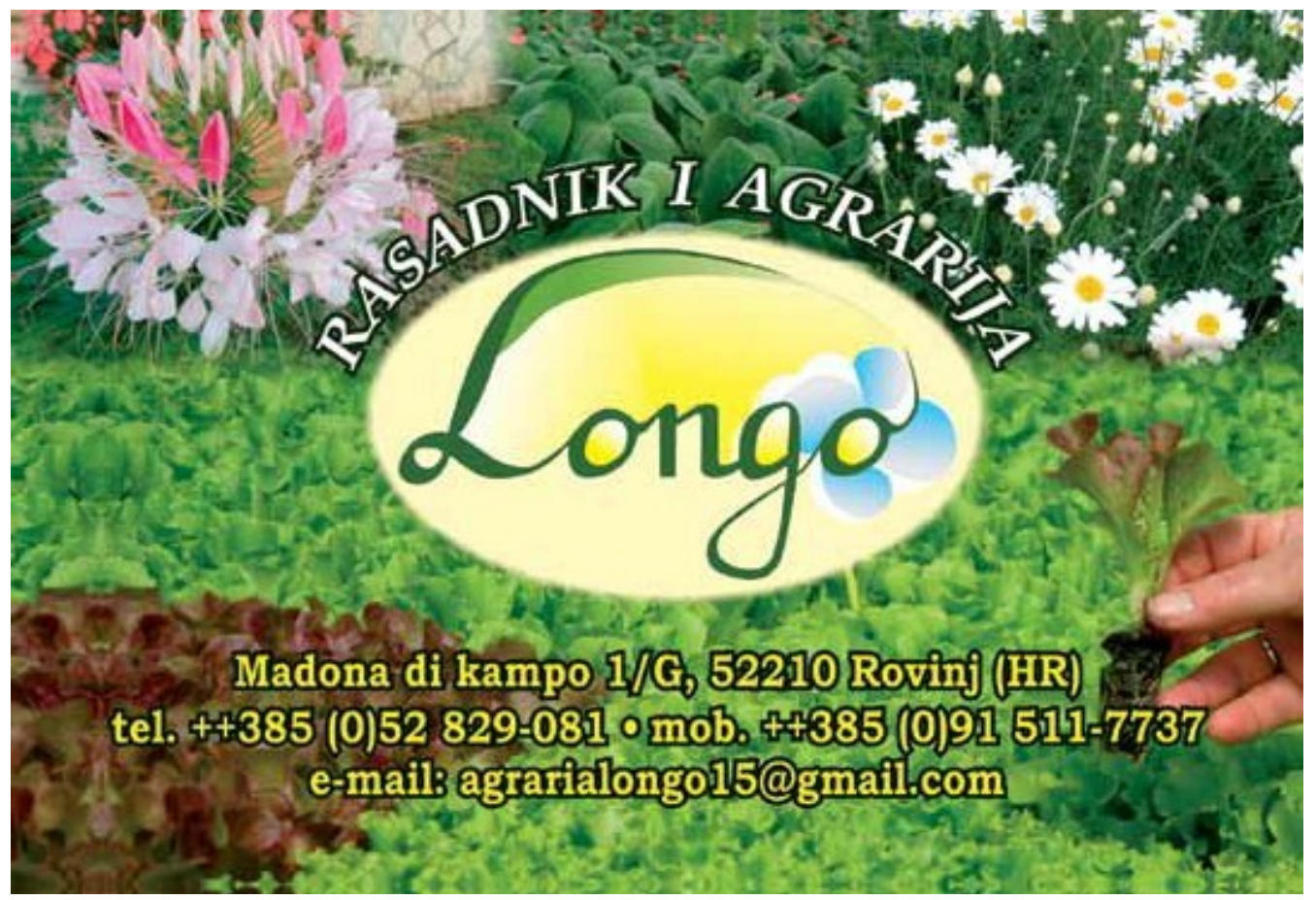

